\title{
Cellular and Molecular Mechanisms Underlying Learning and Memory Impairments Produced by Cannabinoids
}

\author{
Jane M. Sullivan ${ }^{1}$ \\ Molecular Neurobiology Laboratory, The Salk Institute, La Jolla, California 92037 USA
}

\begin{abstract}
Why does smoking marijuana impair learning and memory? Behavioral studies suggest that a disruption of normal hippocampal function contributes to these deficits. In vitro experiments find that cannabinoid receptor activation reduces neurotransmitter release below the levels required to trigger long-term changes in synaptic strength in the hippocampus. Cannabinoids reduce glutamate release through a G-protein-mediated inhibition of the calcium channels responsible for neurotransmitter release from hippocampal neurons. These mechanisms likely play a role in the learning and memory impairments produced by cannabinoids and by endogenous cannabinoid receptor ligands.
\end{abstract}

Learning and memory impairments are among the most commonly reported behavioral effects of cannabinoids, the active ingredients of marijuana. Receptors for cannabinoids are highly expressed in the hippocampus, a brain region that is believed to play an important role in certain forms of learning and memory. It is therefore reasonable to suppose that some of the learning and memory deficits produced by marijuana are due to altered hippocampal function. I will first review briefly behavioral studies suggesting that marijuana does indeed alter hippocampal function, and then focus on in vitro studies that provide insights into the cellular and molecular mechanisms that may underlie the memory deficits produced by marijuana.

\section{Cannabinoids Impair Short-term Memory in Humans, Other Primates, and Rodents}

Behavioral studies in humans show that marijuana acutely impairs performance on short-term memory tasks (Miller and Branconnier 1983; Miller 1984; Chait and Pierri 1992). In particular, marijuana disrupts the ability to freely recall words from a list that has been presented to an intoxicated subject. Free recall is impaired both immediately after list presentation (immediate recall) and $20 \mathrm{~min}$ following list presentation (delayed recall). In the case of immediate free recall, words presented at the end of a list are more likely to be recalled than those presented earlier in the list, suggesting that some aspect of memory storage has been disrupted. In contrast to its effects on free recall, marijuana has no effect on recognition of previously presented words within a list of old and new words. Additional memory deficits produced by marijuana include inconsistent retrieval from long-term memory storage (impaired free recall of words

${ }^{1}$ Corresponding author.

E-MAIL janes@AXP2.Salk.edu; FAX (858) 450-2172. presented at least 1 week earlier to undrugged subjects) and memory intrusions (recall of words not presented within the list). This pattern of memory deficits seen following marijuana intoxication is similar to that seen in patients with hippocampal dysfunction induced by herpes simplex encephalitis, Korsakoff syndrome, or Alzheimer's disease (Miller and Branconnier 1983; Miller 1984).

Experiments in animals support the connection between cannabinoid-mediated memory deficits and impairment of hippocampal function. In monkeys, administration of $\Delta^{9}$-tetrahydrocannabinol (THC), one of the principal psychoactive cannabinoids found in marijuana, prior to testing impairs performance of a delayed nonmatch-to-sample memory task, in which the animal must identify which of a presented pair of objects was displayed 15 min earlier (Aigner 1988). In contrast, cannabinoids have no effect on concurrent discrimination learning, during which the drugged animal must learn, over several sessions separated by $24 \mathrm{hr}$, to identify which of two objects is always paired with food. This differential effect of THC on delayed nonmatch-to-sample performance and concurrent discrimination learning is reminiscent of the pattern of deficits seen after amygdalo-hippocampal lesions in monkeys (Aigner 1988).

Cannabinoids impair performance of a variety of memory tasks in rats (Hampson and Deadwyler 1998). For example, in rats that have been trained to respond to a conditioned tone stimulus ( $\mathrm{CS}^{+}$tone) with a nosepoke, THC increases response latency and decreases the percentage of correct responses (Campbell et al. 1986a). These deficits suggest an inability to process and/or recall the recently presented tone correctly. THC also impairs performance on a delayed match-to-sample memory task in rats, but only when the delay interval is increased beyond $5 \mathrm{sec}$ (Heyser et

LEARNING \& MEMORY 7:132-139 @ 2000 by Cold Spring Harbor Laboratory Press ISSN1072-0502/00 \$5.00

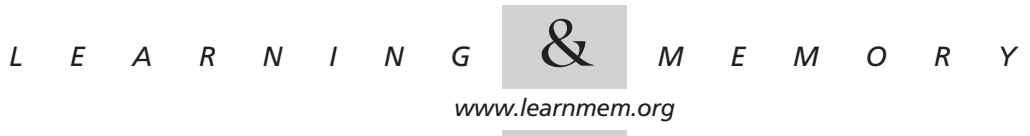


al. 1993). The absence of an effect at short delay times indicates that cannabinoids do not impair the ability to perform the basic task, but instead produce a selective learning and/or memory deficit. This time dependence of the behavioral deficits in the delayed match-to-sample task, that is, the lack of effect of THC on performance after very brief delays between sample and match phases and increasing impairment of performance with increasing delay, is again identical to the pattern of deficits produced by hippocampal lesions (Heyser et al. 1993). In summary, cannabinoids impair performance of a wide variety of memory tasks in humans, nonhuman primates, and rodents that share the common feature of requiring the hippocampus for normal performance. These results are consistent with a cannabinoidmediated deficit in hippocampal function.

\section{Cannabinoids Alter Hippocampal Responsiveness}

In addition to its effects on behavior, THC also significantly alters the average evoked potentials recorded from the dentate gyrus in the hippocampus elicited by a $\mathrm{CS}^{+}$tone (Campbell et al. 1986a). The change in shape of the evoked potential waveform is consistent with a decrease in transmission of sensory information between the entorhinal cortex and the dentate gyrus carried by the perforant pathway. In addition, THC suppresses both spontaneous and $\mathrm{CS}^{+}$toneevoked activity of individual granule cells in the dentate gyrus, while having no effect on $\mathrm{CS}^{+}$tone-evoked activity in the inferior colliculus (Campbell et al. 1986b). The latter observation indicates that cannabinoids are not affecting all parts of the brain equally; hippocampal responses to sensory stimuli are specifically decreased, whereas responses to auditory stimuli at lower relay centers in the brain remain intact. This decreased sensory responsiveness is likely to contribute to the cannabinoid-induced performance deficits observed in certain learning and memory tasks.

Cannabinoids also alter firing patterns in the CA1 region of the hippocampus. Extracellular recordings from CA1 neurons made during delayed match-to-sample testing show that THC eliminates the marked increase in firing that occurs normally in these cells during the sampling phase of the task, and more subtly alters the pattern of firing that occurs during the delay and match phases (Heyser et al. 1993). The nonuniformity of these effects indicates that cannabinoids are not causing a nonspecific effect on excitability. The pronounced inhibition of firing during the sampling phase suggests a possible mechanism for the behavioral deficits if, as has been proposed by Heyser et al. (1993), firing during this phase reflects the encoding of information that is required for correct performance during the match phase of the task.

Further support for the idea that cannabinoids are affecting learning and memory through alterations in hippocampal cell activity comes from studies showing that the memory impairing effects of systemic cannabinoid administration can be reproduced by intrahippocampal administration of cannabinoid receptor agonists (Lichtman et al. 1995). For this study, rats were pretrained in an undrugged state on an eight arm radial maze, a task that specifically measures spatial memory, the kind of memory that is most clearly associated with hippocampal function in rats. Once the rats learned the maze task, they were tested after systemic administration of THC or other cannabinoid receptor agonists. THC or the other agonists increased the percentage of rats that failed the maze, either by revisiting two or more arms or by failing to visit all eight arms. Direct injection of cannabinoid receptor agonist in the dentate gyrus, CA1, or CA3 region of the hippocampus produced an increase in failure rate identical to that produced by systemic administration (Lichtman et al. 1995). Importantly, these intrahippocampal injections failed to produce analgesia, catalepsy, or hypothermia (three effects produced by systemic administration of cannabinoids) suggesting that a selective disruption of the hippocampus is contributing in an important way to cannabinoid-mediated impairment of performance of this memory task.

\section{Cannabinoid Receptors Are Found at High Density in the Hippocampus}

To date, two types of cannabinoid receptors have been identified, CB1 and CB2 (Matsuda et al. 1990; Munro et al. 1993). Both are classic G-protein-coupled receptors containing seven transmembrane domains (Howlett et al. 1992; Howlett 1995). CB1 is found throughout the CNS, whereas CB2 has thus far been localized primarily in peripheral tissues. CB1 receptors are expressed at especially high density in the dentate gyrus, CA1, and CA3 regions of the hippocampus (Herkenham et al. 1990; Matsuda et al. 1990; Herkenham et al. 1991; Tsou et al. 1998), although there is currently some question about whether CB1 receptors can be found in excitatory pyramidal neurons (Pettit et al. 1998) or are instead localized exclusively in the presynaptic terminals of cholecystokinin-positive inhibitory interneurons (Katona et al. 1999; Tsou et al. 1999). The latter groups use the same antibody and report that $>90 \%$ of all detectable CB1-expressing cells in CA1 and CA3 are cholecystokinincontaining GABA-ergic interneurons. Pettit et al. (1998) use a different antibody and observe intense positive staining for $\mathrm{CB} 1$ in pyramidal neurons throughout CA1 and CA3. In either case, the presence of cannabinoid receptors within the hippocampus supports the notion that these drugs have a direct effect on the hippocampus, thereby impairing those forms of learning and memory that require normal functioning of this part of the brain.

\section{Cannabinoids Inhibit Hippocampal Long-term Potentiation and Long-term Depression}

Long-term potentiation (LTP) and long-term depression

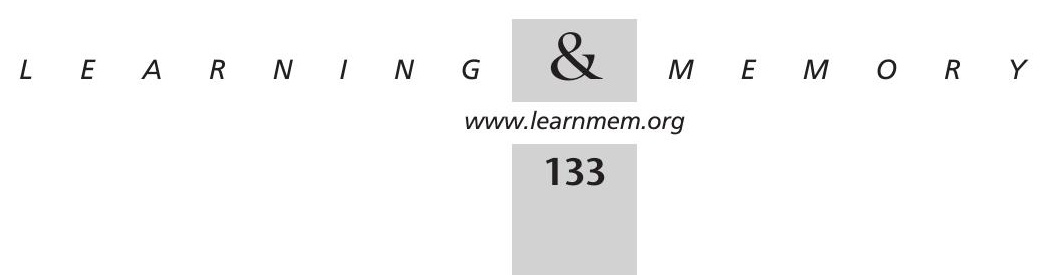


(LTD) of CA3-CA1 synaptic transmission are two in vitro models for learning and memory. Hippocampal LTP is typically induced either by applying high-frequency (i.e., 100 $\mathrm{Hz}$ ) stimuli to CA3 afferents or by pairing presynaptic stimulation with postsynaptic depolarization, either of which relieves magnesium blockade of NMDA-type glutamate receptors and allows calcium to enter through these channels (Malenka and Nicoll 1993; Nicoll and Malenka 1995). The entry of calcium through NMDA receptor channels is known to be a critical trigger for the formation of LTP. LTD is induced most commonly by stimulating CA3 axons at 1-5 $\mathrm{Hz}$ and is also dependent on the entry of calcium through NMDA-gated channels (Bear and Abraham 1996).

Cannabinoid receptor activation inhibits both LTP and LTD induction in the hippocampus. Activation of CB1 receptors blocks LTP of field potentials in the CA1 region (Nowicky et al. 1987; Collins et al. 1994; Collins et al. 1995; Terranova et al. 1995; Misner and Sullivan 1999) and has been found recently to inhibit hippocampal LTD of CA1 field potentials as well (Misner and Sullivan 1999). Although the cellular and molecular changes underlying LTP and LTD have yet to be connected definitively to learning, evidence to date suggests that changes such as these are likely to mediate some forms of memory (Stevens 1998). Understanding the mechanism by which cannabinoids inhibit hippocampal LTP and LTD may therefore provide a clue to the cellular and molecular mechanisms underlying some of the cannabinoid-induced learning and memory impairments. What might these mechanisms be?

\section{Cannabinoids Decrease Release of Acetylcholine and GABA from the Hippocampus}

Acetylcholine, GABA, and glutamate are three neurotransmitter systems through which cannabinoids could be exerting their effects in the hippocampus. The potent and selective cannabinoid receptor agonist WIN55,212-2 inhibits release of acetylcholine from the hippocampi of freely moving rats (Gessa et al. 1997) and from electrically stimulated rat hippocampal slices (Gifford and Ashby 1996). Most of the transmitter detected in these studies was released from cholinergic hippocampal neurons located in the medial septum and diagonal band of Broca. Given that the septohippocampal pathway is important for learning and memory, it is reasonable to suppose that inhibition of this cholinergic pathway is one of the means by which cannabinoids impair learning and memory (Gifford and Ashby 1996). This hypothesis is challenged however, by the finding that pretreatment with the cholinesterase inhibitor physostigmine fails to attenuate the impairments in radial arm maze performance produced by THC (Lichtman and Martin 1996). Additionally, administration of a potent CB1 receptor antagonist, SR141716A, has no effect on the impairments induced by cholinergic receptor antagonist scopolamine (Lichtman and Martin 1996). These results argue against an interaction between the cannabinoid and cholinergic receptor systems in the spatial memory deficits produced by cannabinoid and cholinergic drugs.

If cannabinoids are not impairing memory via an interaction with cholinergic transmission in the hippocampus, then perhaps they are acting by enhancing GABA-ergic feedback inhibition, an important modulator of synaptic transmission in the hippocampus. This possibility is consistent with the finding that cannabinoid receptor activation reduces paired-pulse facilitation of perforant path field potentials recorded in the dentate gyrus (Kirby et al. 1995). Paired-pulse facilitation refers to the following phenomenon: When two presynaptic stimuli are applied at short time intervals, the second response is often larger than the first. Treatments that reduce neurotransmitter release typically increase paired-pulse facilitation. The response of the perforant path field potentials to WIN55,212-2 is atypical because the drug reduces both the field potential and its paired-pulse facilitation. Although unexpected, the WIN55,212-2-mediated reduction of paired-pulse facilitation is reminiscent of the effect of $\mathrm{GABA}_{\mathrm{B}}$ receptor agonist baclofen, which is believed to act via presynaptic inhibition of neurotransmitter release. To determine whether cannabinoid receptor agonist reduces paired-pulse facilitation through a similar mechanism, WIN55,212-2 and baclofen were sequentially administered (Kirby et al. 1995). These two drugs were equally effective in reducing facilitation, but simultaneous application produced no greater inhibition than either one alone, suggesting that cannabinoids and $\mathrm{GABA}_{\mathrm{B}}$ receptor activators may act through a common pathway.

Setting out to test directly the hypothesis that cannabinoids inhibit hippocampal long-term synaptic plasticity via an upregulation of GABA-ergic synaptic transmission, Paton et al. (1998) measured both paired-pulse responses and LTP of the population spike in the CA1 region of the hippocampus. The amplitude of this extracellularly recorded population spike is proportional to the number of CA1 pyramidal neurons that fire action potentials in response to synaptic input from CA3 axons. The depression of the second population spike relative to the first at short interpulse intervals $(<100 \mathrm{msec})$ in response to strong electrical stimuli (i.e., stimuli that elicit pyramidal cell firing) reflects the strength of GABA-ergic feedback inhibition triggered by pyramidal cell activity. As expected, WIN55,212-2 application inhibited LTP in a dose-dependent manner. In contrast to results previously reported using THC (Vardaris and Weisz 1977; Weisz et al. 1982), Paton et al. (1998) found that WIN55,212-2 application reduced paired-pulse depression in CA1. This result suggests that $\mathrm{CB} 1$ receptor activation reduces GABA-ergic transmission in the hippocampus. In support of this hypothesis, cannabinoid receptor activation decreased the evoked release of radiolabeled GABA from hippocampal slices (Katona et al. 1999). Al-

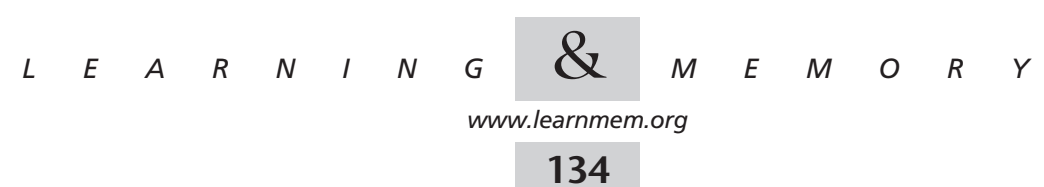


though a decrease in GABA release may be responsible for altered hippocampal function underlying some of the behavioral effects of marijuana, it probably cannot explain the CB1 receptor-mediated inhibition of long-term synaptic plasticity. Both LTP and LTD are elicited routinely in the hippocampus in the presence of GABA-ergic transmission blockers. By what other mechanisms could CB1 receptor activation be blocking these electrophysiological models for learning and memory?

\section{Cannabinoids Decrease Release of Glutamate from the Hippocampus}

Glutamate is a third neurotransmitter through which cannabinoids might be mediating their effects on learning and memory. Using optical imaging of calcium spikes to monitor synaptic activity in cultured hippocampal neurons, CB1 receptor activation by either THC or WIN55,212-2 reduces glutamatergic transmission (Shen et al. 1996; Shen and Thayer 1999). Electrophysiological measurements show that WIN55,212-2 application decreases the evoked excitatory postsynaptic current (EPSC) in these neurons (Shen et al. 1996; Shen and Thayer 1999; Sullivan 1999), while having no effect on the response to exogenously applied kainate or NMDA (Shen et al. 1996). The lack of effect of WIN55,212-2 on the NMDA response rules out inhibition of NMDA receptor channels as a mechanism for cannabinoid receptor-mediated inhibition of LTP and LTD. Treatment of the cultured neurons with pertussis toxin, which inactivates $G_{i / o}$ protein subunits, blocks the effects of WIN55,212-2 on EPSC size (Shen et al. 1996; Sullivan 1999). These results suggest strongly that cannabinoids decrease the release of glutamate through a presynaptic mechanism mediated by an inhibitory G-protein. This conclusion is supported by recent work using hippocampal slices showing that cannabinoid receptor activation reduces EPSCs at CA3CA1 synapses with no change in postsynaptic sensitivity to neurotransmitter monitored by spontaneous miniature EPSC amplitude (Misner and Sullivan 1999). Cannabinoid receptor activation also increases the paired-pulse facilitation of EPSCs measured at 20- to 200-msec intervals in the presence of a GABA-ergic current blocker, conditions used traditionally to monitor changes in presynaptic release probability. These findings suggest a cellular mechanism underlying the cannabinoid-mediated inhibition of longterm synaptic plasticity - a decrease in release of excitatory neurotransmitter to a level below that required for relief of magnesium blockade of NMDA receptors.

Because hippocampal LTP and LTD require depolarization of the postsynaptic membrane to relieve magnesium blockade of NMDA receptors and allow entry of calcium (Malenka and Nicoll 1993; Nicoll and Malenka 1995), a reduction in neurotransmitter release could impair long-term synaptic plasticity by failing to depolarize the postsynaptic CA1 membrane to a level that relieves magnesium block. To test this hypothesis, stimuli used typically to induce LTP and LTD were applied to hippocampal slices in the presence of CB1 agonist WIN55,212-2 while holding the postsynaptic membrane at a depolarized potential that relieved magnesium blockade. Under these conditions, whole-cell LTP and LTD can be induced successfully (Misner and Sullivan 1999). LTP and LTD of CA1 field potentials are also induced in the presence of WIN55,212-2 when magnesium is omitted from the external recording solution. These results support the notion that cannabinoids impair long-term synaptic plasticity, and perhaps learning and memory, not through any direct effect on the molecular machinery underlying LTP and LTD, but simply by reducing neurotransmitter release from presynaptic terminals. What molecular mechanisms might be responsible for this reduction in transmitter release?

\section{Molecular Mechanisms Underlying Cannabinoid-mediated Reduction in Neurotransmitter Release}

There are several excellent candidates for the final molecular targets of the cannabinoid receptor signal transduction pathway. Studies using heterologous expression systems have found that inwardly rectifying potassium channels (Henry and Chavkin 1995; Mackie et al. 1995) as well as P/Q- and N-type calcium channels (Mackie and Hille 1992; Mackie et al. 1995) are modulated by cannabinoids. Enhancement of potassium currents and/or inhibition of the $\mathrm{P} / \mathrm{Q}$ - and N-type calcium currents that are responsible for coupling depolarization of the presynaptic terminal with release of neurotransmitter, are means by which cannabinoids could inhibit release. In hippocampal neurons in culture, cannabinoids enhance the transient voltage-sensitive potassium current $I_{A}$ (Deadwyler et al. 1995), which would be expected to reduce transmitter release by shortening the duration of the action potential. The contribution of cannabinoid mediated modulation of potassium channels to the observed reduction in transmitter release is brought into question, however, by the absence of an effect of cannabinoid receptor activation on the fiber volleys recorded in hippocampal slice preparations (Ameri et al. 1999; Misner and Sullivan 1999). In cultured hippocampal neurons, cannabinoid receptor activation has no effect on action potential threshold, duration, amplitude, or on the resting membrane potential (Shen et al. 1996). These findings suggest that modulation of potassium currents is not a primary mechanism by which cannabinoids modulate synaptic transmission in the hippocampus.

Cannabinoid receptor activation inhibits $\mathrm{N}$ - and $\mathrm{P} / \mathrm{Q}-$ type calcium channels in cultured hippocampal neurons while having no effect on L-type calcium channels (Twitchell et al. 1997; Shen and Thayer 1998). Inhibition of these calcium channels would be expected to reduce transmitter release because calcium entry through these chan-

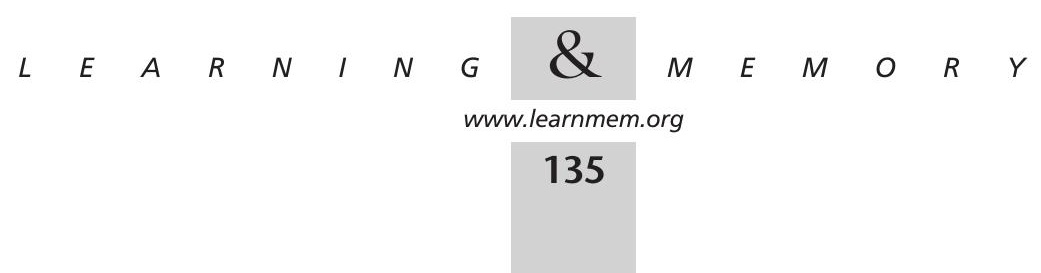


nels is known to be required for release of transmitter from hippocampal synapses (Takahashi and Momiyama 1993; Wheeler et al. 1994). To test the hypothesis that cannabinoids mediate their effects on transmission in the hippocampus by inhibiting $\mathrm{N}$ - and $\mathrm{P} / \mathrm{Q}$-type calcium channels, the effects of cannabinoid receptor activation were measured before and after pharmacological blockade of these channels (Sullivan 1999). Application of the calcium channels blockers reduces the EPSC in cultured hippocampal neurons to about one-tenth of its original size but cannabinoid receptor agonists are no longer effective in reducing the EPSC. To make sure that this effect is due to occlusion of the final molecular targets of cannabinoid receptor activation, and not to a minimal requirement for calcium in the presynaptic terminal for cannabinoids' effects, WIN55,212-2 was applied before and after a reduction in extracellular calcium that produces a decrease in EPSC size comparable to that produced by the selective calcium channel blockers. When the EPSC is reduced by decreasing extracellular calcium, cannabinoid receptor activation effectively inhibits the remaining current (Sullivan 1999).

Cannabinoid receptor activation may also reduce transmitter release through a direct effect on vesicle release machinery. WIN55,212-2 application decreases the frequency

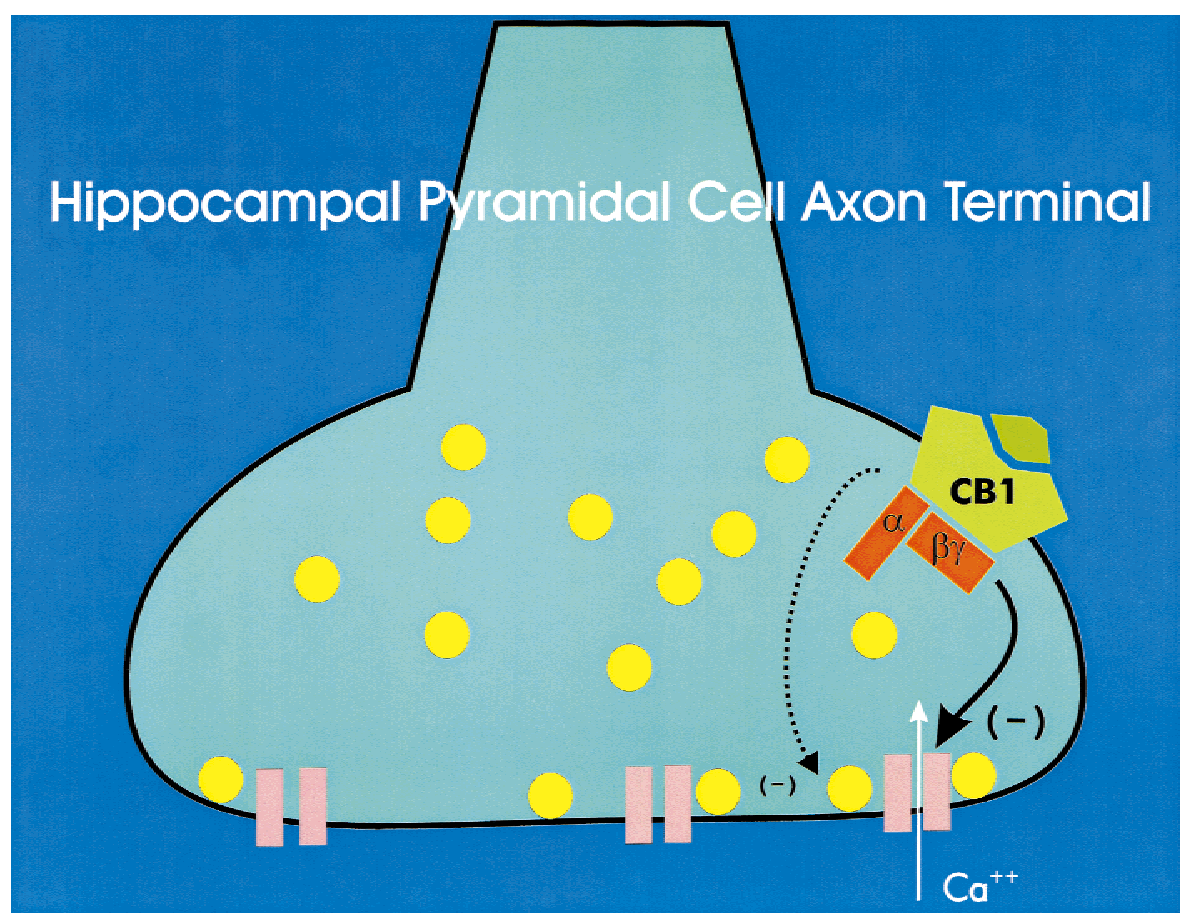

Figure 1 Candidate mechanisms for cannabinoid receptor-mediated inhibition of glutamate release from hippocampal pyramidal neurons. Binding of ligand to the CB1 receptor causes dissociation of the $\alpha$ and $\beta \gamma$ subunits (red) of the $G_{i / o}$-protein that is coupled to the receptor. The $\beta \gamma$ subunits can then interact directly with and inhibit the voltage-dependent $\mathrm{N}$ - and Q-type calcium channels (pink) that are responsible for coupling depolarization of the axon terminal with release of glutamate-filled vesicles (yellow). A second mechanism by which cannabinoids may reduce transmitter release is a direct inhibition of proteins responsible for release of the vesicles. of spontaneous miniature EPSCs (mEPSCs) of pyramidal neurons in hippocampal slices (Misner and Sullivan 1999) and in hippocampal cultures (Sullivan 1999). The frequency of spontaneous mEPSCs at resting membrane potentials is not affected by calcium channel blockers (Scanziani et al. 1992), and is, therefore, not expected to be altered by Nand $\mathrm{P} / \mathrm{Q}$-type calcium channel inhibition. The effects of WIN55,212-2 on mEPSC frequency suggest a direct inhibition of proteins involved in vesicle release that act downstream of calcium entry into the axon terminal. In summary, a G-protein-mediated inhibition of presynaptic N- and P/Qtype calcium channels is likely the primary molecular mechanism by which cannabinoids inhibit release of glutamate in the hippocampus, but modulation of proteins involved in vesicle release may also play a role (Fig. 1).

\section{Molecular Mechanisms Underlying G-protein-mediated Effects of Cannabinoid Receptor Activation}

How does G-protein activation lead to the inhibition of presynaptic calcium channels? In several brain areas, including cerebellum and striatum, activation of G-proteins via cannabinoid receptors inhibits basal adenylyl cyclase activity and decreases intracellular levels of cAMP (Bidaut-Russell et al. 1990; Pacheco et al. 1991; Childers et al. 1994). In theory, this decrease in cAMP levels could alter the activity of cAMP-dependent protein kinase, which in turn, could inhibit calcium channel currents. However, cannabinoid receptor activation has no effect on basal levels of adenylyl cyclase activity or cAMP in the hippocampus, although it can reduce forskolin-stimulated cAMP accumulation (Deadwyler et al. 1995). In addition, nonhydrolyzable cAMP analogs that inhibit cAMP-mediated processes fail to prevent cannabinoid receptor-mediated inhibition of N-type calcium channels (Mackie and Hille 1992). In light of these findings, it is unlikely that cannabinoids inhibit transmitter release in the hippocampus via Gprotein-mediated inhibition of adenylyl cyclase, although this pathway likely plays an important role in cannabinoid-mediated effects in other brain regions.

Recent data show that G-protein $\beta \gamma$ subunits directly inhibit $\mathrm{N}$ and $\mathrm{P} / \mathrm{Q}$-type calcium channels.

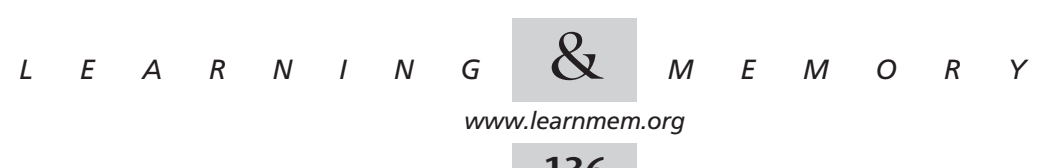


After ligand binding to a G-protein coupled receptor causes dissociation of the $\alpha$ subunit from the $\beta \gamma$ subunits, the $\beta \gamma$ subunits bind directly to $\mathrm{N}$ - and $\mathrm{P} / \mathrm{Q}$-type calcium channels and reduce current flow (Dolphin 1998). While no experiments to date have tested directly the hypothesis that this mechanism underlies cannabinoid-receptor mediated inhibition of presynaptic calcium channels, it is a most reasonable candidate.

\section{Evidence for a Role for Endogenous Cannabinoid Receptor Ligands in Learning and Memory}

The presence of a cannabinoid receptor activated signal transduction pathway in the hippocampus begs the question, what are the endogenous ligands for these receptors and what role does their activation normally play in learning and memory? Two endogenous ligands have been identified to date, anandamide (Devane et al. 1992) and 2-arachidonylglycerol (2-AG; Stella et al. 1997), both phospholipid derivatives. Anandamide is found in the hippocampus of humans and rats (Felder et al. 1996), while the localization of 2-AG remains to be determined. Application of either anandamide or 2-AG inhibits LTP of hippocampal field EPSPs (Terranova et al. 1995; Stella et al. 1997). Although some earlier studies failed to find an effect of anandamide on memory tasks (i.e., Crawley et al. 1993; Lichtman et al. 1995), this could be due to the instability of this compound (Childers and Breivogel 1998). More recent work done with metabolically stabilized anandamide has revealed inhibitory effects on learning and memory (Mallet and Beninger 1996; Brodkin and Moerschbaecher 1997).

Some evidence suggests that the endogenous cannabinoid system may be tonically active. Application of CB1 receptor antagonist alone potentiates acetylcholine release from hippocampi of freely moving rats (Gessa et al. 1997) and from electrically stimulated rat hippocampal slices (Gifford and Ashby 1996). CB1 receptor antagonist also facilitates short-term olfactory memory in a social recognition test that requires hippocampal processing (Terranova et al. 1996). Although these results are consistent with a role for chronic activation of $\mathrm{CB} 1$ receptors in learning and memory, this interpretation is still unconfirmed because SR141716A, the CB1 receptor antagonist used for these studies, may also act as an inverse agonist at these receptors (Landsman et al. 1997). If SR141716A is indeed serving not only to inhibit binding and activation by CB1 receptor ligands but also to suppress tonic constitutive activity of the unoccupied receptor, then identification of the function of endogenous cannabinoid receptors may have to await the development of pharmacological reagents with more selective actions. However, the recent finding that genetically modified mice lacking CB1 receptors exhibit enhanced LTP (Bohme et al. 2000) supports the hypothesis that endogenous cannabinoids play a role in learning and memory.

\section{Summary Conclusions and Future Directions}

The studies reviewed here suggest that the learning and memory deficits produced by marijuana result from a reduction in transmitter release below the levels required to trigger long-term synaptic changes that underlie memory formation. This decreased release of transmitter is due primarily to a G-protein-mediated inhibition of presynaptic calcium channels that modulate transmitter release. The identity of the transmitter (or peptide) whose release is directly reduced by cannabinoid receptor activation is still an open question. The electrophysiological results are most consistent with a reduction of glutamate release in the CA1 region of the hippocampus, while immunohistochemistry suggests that $\mathrm{CB} 1$ receptors are localized exclusively in cholecystokinin-positive inhibitory interneurons.

The resolution of this discrepancy is the next challenge for the field. The effects of cannabinoids on inhibitory GABA-ergic synaptic transmission must be investigated. Because the interplay between excitatory and inhibitory transmission is complex, these studies may still not fully explain the effects of cannabinoids on inputs to, processing within, and output from the hippocampal circuit. A complete picture will emerge only when we understand the effect of cannabinoids on each type of hippocampal neuron and the relative contribution of these effects on hippocampal output.

What is true for the hippocampus may or may not be true for other brain regions. Few studies to date have looked at the synaptic effects of cannabinoids in higher cortical areas that are critical for information processing, although cannabinoid receptors are found in these areas. Different and/or additional mechanisms may mediate cannabinoid effects in these brain regions and need to be studied. For example, in cultured cerebellar neurons, cannabinoid receptor activation enhances release from intracellular calcium stores (Netzeband et al. 1999). Although this mechanism is unlikely to have a direct effect on transmitter release, it could affect profoundly synaptic transmission through second messenger pathways. It will be important to determine whether this mechanism is operating in other parts of the brain. In addition, inhibition of adenylyl cyclase is clearly a major contributor to cannabinoid receptor-mediated effects in several brain regions and may play a role in cannabinoid effects in areas important for learning and memory.

Finally, the role of endogenous cannabinoid receptor ligands in learning and memory formation must be elucidated. What triggers release of endogenous cannabinoids? What are the effects of this release? Are the effects of endogenous cannabinoids identical to those of exogenous agonists? These questions will keep researchers in the field busy for several years to come. Understanding the cellular and molecular mechanisms underlying cannabinoid-mediated impairments of learning and memory may aid in the

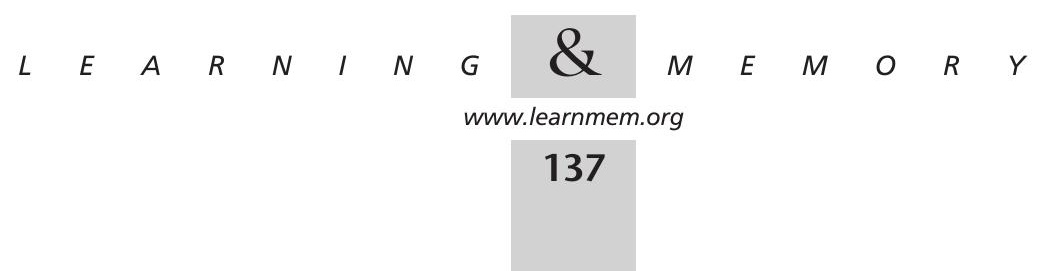


design of therapeutic agents having the beneficial properties of cannabinoids without their negative psychoactive side effects (Hollister 1984) and also provide insights into the normal function of $\mathrm{CB} 1$ receptors in the central nervous system.

\section{ACKNOWLEDGMENTS}

I thank Drs. Sascha Du Lac, Dana Vaughan, and Jeffry Isaacson for their helpful comments on this manuscript. Preparation of the manuscript was supported by a grant from the National Institute on Drug Abuse.

\section{REFERENCES}

Aigner, T.G. 1988. Delta-9-tetrahydrocannabinol impairs visual recognition memory but not discrimination learning in rhesus monkeys. Psychopharmacology 95: 507-511.

Ameri, A., A. Wilhelm, and T. Simmet. 1999. Effects of the endogeneous cannabinoid, anandamide, on neuronal activity in rat hippocampal slices. Br. J. Pharmacol. 126: 1831-1839.

Bear, M.F. and W.C. Abraham. 1996. Long-term depression in hippocampus. Ann. Rev. Neurosci. 19: 437-462.

Bidaut-Russell, M., W.A. Devane, and A.C. Howlett. 1990. Cannabinoid receptors and modulation of cyclic AMP accumulation in the rat brain. J. Neurochem. 55: 21-26.

Bohme, G.A., M. Laville, C. Ledent, M. Parmentier, and A. Imperato. 2000. Enhanced long-term potentiation in mice lacking cannabinoid CB1 receptors. Neuroscience 95: 5-7.

Brodkin, J. and J.M. Moerschbaecher. 1997. SR141716A antagonizes the disruptive effects of cannabinoid ligands on learning in rats. $J$. Pharmacol. Exp. Ther. 282: 1526-1532.

Campbell, K.A., T.C. Foster, R.E. Hampson, and S.A. Deadwyler. 1986a. delta 9-Tetrahydrocannabinol differentially affects sensory-evoked potentials in the rat dentate gyrus. J. Pharmacol. Exp. Ther. 239: 936-940

Campbell, K.A., T.C. Foster, R.E. Hampson, and S.A. Deadwyler. 1986b. Effects of delta 9-tetrahydrocannabinol on sensory-evoked discharges of granule cells in the dentate gyrus of behaving rats. J. Pharmacol. Exp. Ther. 239: 941-945.

Chait, L.D. and J. Pierri. 1992. The cannabinoid receptor. In Marinjuana/cannabinoids: Neurobiology and neurophysiology (eds L. Murphy and A. Bartke), pp. 387-423. CRC Press, Boca Raton, FL.

Childers, S.R. and C.S. Breivogel. 1998. Cannabis and endogenous cannabinoid systems. Drug Alcohol Depend. 51: 173-187.

Childers, S.R., T. Sexton, and M.B. Roy. 1994. Effects of anandamide on cannabinoid receptors in rat brain membranes. Biochem. Pharmacol. 47: 711-715.

Collins, D.R., R.G. Pertwee, and S.N. Davies. 1994. The action of synthetic cannabinoids on the induction of long-term potentiation in the rat hippocampal slice. Eur. J. Pharmacol. 259: R7-8.

Collins, D.R., R.G. Pertwee, and S.N. Davies. 1995. Prevention by the cannabinoid antagonist, SR141716A, of cannabinoid-mediated blockade of long-term potentiation in the rat hippocampal slice. Brit. J. Pharmacol. 115: 869-870.

Crawley, J.N., R.L. Corwin, J.K. Robinson, C.C. Felder, W.A. Devane, and J. Axelrod. 1993. Anandamide, an endogenous ligand of the cannabinoid receptor, induces hypomotility and hypothermia in vivo in rodents. Pharmacol. Biochem. Behav. 46: 967-972.

Deadwyler, S.A., R.E. Hampson, J. Mu, A. Whyte, and S. Childers. 1995. Cannabinoids modulate voltage sensitive potassium A-current in hippocampal neurons via a cAMP-dependent process. J. Pharmacol. Exp. Ther. 273: 734-743.

Devane, W.A., L. Hanus, A. Breuer, R.G. Pertwee, L.A. Stevenson, G. Griffin, D. Gibson, A. Mandelbaum, A. Etinger, and R. Mechoulam. 1992. Isolation and structure of a brain constituent that binds to the cannabinoid receptor. Science 258: 1946-1949.
Dolphin, A.C. 1998. Mechanisms of modulation of voltage-dependent calcium channels by G proteins. J. Physiol. Ser. (Lond) 506: 3-11

Felder, C.C., A. Nielsen, E.M. Briley, M. Palkovits, J. Priller, J. Axelrod, D.N. Nguyen, J.M. Richardson, R.M. Riggin, G.A. Koppel et al. 1996. Isolation and measurement of the endogenous cannabinoid receptor agonist, anandamide, in brain and peripheral tissues of human and rat. FEBS Lett. 393: 231-235.

Gessa, G.L., M.S. Mascia, M.A. Casu, and G. Carta. 1997. Inhibition of hippocampal acetylcholine release by cannabinoids: Reversal by SR 141716A. Eur. J. Pharmacol. 327: R1-2.

Gifford, A.N. and C.R. Ashby, Jr. 1996. Electrically evoked acetylcholine release from hippocampal slices is inhibited by the cannabinoid receptor agonist, WIN 55212-2, and is potentiated by the cannabinoid antagonist, SR 141716A. J. Pharmacol. Exp. Ther. 277: 1431-1436.

Hampson, R.E. and S.A. Deadwyler. 1998. Role of cannabinoid receptors in memory storage. Neurobiol. Dis. 5: 474-482.

Henry, D.J. and C. Chavkin. 1995. Activation of inwardly rectifying potassium channels (GIRK1) by co- expressed rat brain cannabinoid receptors in Xenopus oocytes. Neurosci. Lett. 186: 91-94.

Herkenham, M., A.B. Lynn, M.D. Little, M.R. Johnson, L.S. Melvin, and B.R. De Costa. 1990. Cannabinoid receptor localization in brain. Proc. Natl. Acad. Sci. 87: 1932-1936.

Herkenham, M., A.B. Lynn, M.R. Johnson, L.S. Melvin, B.R. de Costa, and K.C. Rice. 1991. Characterization and localization of cannabinoid receptors in rat brain: A quantitative in vitro autoradiographic study. $J$. Neurosci. 11: 563-583.

Heyser, C.J., R.E. Hampson, and S.A. Deadwyler. 1993. Effects of Delta-9-Tetrahydrocannabinol on delayed match to sample performance in rats: Alterations in short-term memory associated with changes in task specific firing of hippocampal cells. J. Pharmacol. Exp. Ther. 264: 294-307.

Hollister, L.E. 1984. Health aspects of cannabis use. In The cannabinoids: Chemical, pharmacological and therapeutic aspects (eds. S. Agurell, W.L. Dewey, and R.E. Willette), pp. 3-20. Academic Press, New York, NY.

Howlett, A.C. 1995. Pharmacology of cannabinoid receptors. Ann. Rev. Pharmacol. Toxicol. 35: 607-634.

Howlett, A.C., D.M. Evans, and D.B. Houston. 1992. The cannabinoid receptor. In Marinjuana/cannabinoids: Neurobiology and neurophysiology (eds. L. Murphy and A. Bartke), pp. 35-72. CRC Press, Boca Raton, FL.

Katona, I., B. Sperlagh, A. Sik, A. Kafalvi, E.S. Vizi, K. Mackie, and T.F. Freund. 1999. Presynaptically located CB1 cannabinoid receptors regulate GABA release from axon terminals of specific hippocampal interneurons. J. Neurosci. 19: 4544-4558.

Kirby, M.T., R.E. Hampson, and S.A. Deadwyler. 1995. Cannabinoids selectively decrease paired-pulse facilitation of perforant path synaptic potentials in the dentate gyrus in vitro. Brain Res. 688: 114-120.

Landsman, R.S., T.H. Burkey, P. Consroe, W.R. Roeske, and H.I. Yamamura. 1997. SR141716A is an inverse agonist at the human cannabinoid CB1 receptor. Eur. J. Pharmacol. 334: R1-2.

Lichtman, A.H. and B.R. Martin. 1996. Delta 9-tetrahydrocannabinol impairs spatial memory through a cannabinoid receptor mechanism. Psychopharmacology Ser. (Berl) 126: 125-131.

Lichtman, A.H., K.R. Dimen, and B.R. Martin. 1995. Systemic or intrahippocampal cannabinoid administration impairs spatial memory in rats. Psychopharmacology Ser. (Berl) 119: 282-290.

Mackie, K. and B. Hille. 1992. Cannabinoids inhibit N-type calcium channels in neuroblastoma-glioma cells. Proc. Natl. Acad. Sci. 89: 3825-3829.

Mackie, K., Y. Lai, R. Westenbroek, and R. Mitchell. 1995. Cannabinoids activate an inwardly rectifying Potassium conductance and inhibit Q-type calcium currents in AtT20 cells transfected with rat brain cannabinoid receptor. J. Neurosci. 15: 6552-6561.

Malenka, R.C. and R.A. Nicoll. 1993. NMDA-receptor-dependent synaptic plasticity: Multiple forms and mechanisms. Trends Neurosci. 16: 521-527.

Mallet, P.E. and R.J. Beninger. 1996. The endogenous cannabinoid

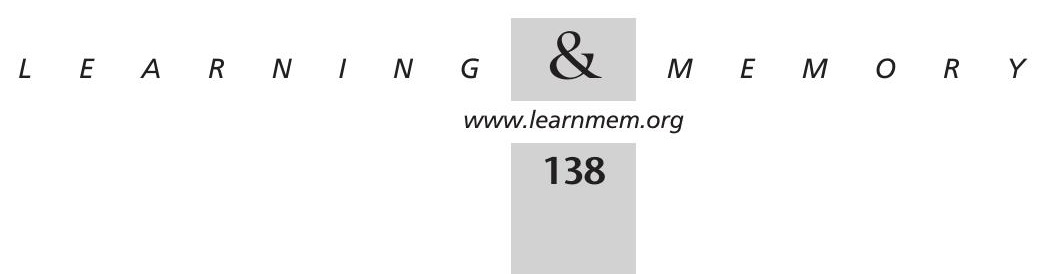


receptor agonist anandamide impairs memory in rats. Behav. Pharmacol. 7: 276-284.

Matsuda, L.A., S.J. Lolait, M.J. Brownstein, A.C. Young, and T.I. Bonner. 1990. Structure of a cannabinoid receptor and functional expression of the cloned cDNA. Nature 346: 561-564.

Miller, L.L. 1984. Marijuana: Acute effects on human memory. In The cannabinoids: Chemical, pharmacological and therapeutic aspects (eds. S. Agurell, W.L. Dewey, and R.E. Willette), pp. 21-46. Academic Press, New York, NY.

Miller, L.L. and R.J. Branconnier. 1983. Cannabis: Effects on memory and the cholinergic limbic system. Psychol. Bull. 93: 441-456.

Misner, D.L. and J.M. Sullivan. 1999. Mechanism of cannabinoid effects on long-term potentiation and depression in hippocampal CA1 neurons. $J$. Neurosci. 19: 6795-6805.

Munro, S., K.L. Thomas, and M. Abu-Shaar. 1993. Molecular characterization of a peripheral receptor for cannabinoids. Nature 365: 61-65.

Netzeband, J.G., S.M. Conroy, K.L. Parsons, and D.L. Gruol. 1999. Cannabinoids enhance NMDA-elicited $\mathrm{Ca}^{2+}$ signals in cerebellar granule neurons in culture. J. Neurosci. 19: 8765-8777.

Nicoll, R.A. and R.C. Malenka. 1995. Contrasting properties of two forms of long-term potentiation in the hippocampus. Nature 377: 115-118.

Nowicky, A.V., T.J. Teyler, and R.M. Vardaris. 1987. The modulation of long-term potentiation by delta-9-tetrahydrocannabinol in the rat hippocampus, in vitro. Brain Res. Bull. 19: 663-672.

Pacheco, M., S.R. Childers, R. Arnold, F. Casiano, and S.J. Ward. 1991. Aminoalkylindoles: Actions on specific G-protein-linked receptors. $J$. Pharmacol. Exp. Ther. 257: 170-183.

Paton, G.S., R.G. Pertwee, and S.N. Davies. 1998. Correlation between cannabinoid mediated effects on paired pulse depression and induction of long term potentiation in the rat hippocampal slice. Neuropharmacol. 37: 1123-1130.

Pettit, D.A., M.P. Harrison, J.M. Olson, R.F. Spencer, and G.A. Cabral. 1998. Immunohistochemical localization of the neural cannabinoid receptor in rat brain. J. Neurosci. Res. 51: 391-402.

Scanziani, M., M. Capogna, B.H. Gähwiler, and S.M. Thompson. 1992. Presynaptic inhibition of miniature excitatory synaptic currents by baclofen and andenosine in the hippocampus. Neuron 9: 919-927.

Shen, M. and S.A. Thayer. 1999. Delta9-tetrahydrocannabinol acts as a partial agonist to modulate glutamatergic synaptic transmission between rat hippocampal neurons in culture. Mol. Pharmacol. 55: 8-13.

Shen, M., T.M. Piser, V.S. Seybold, and S.A. Thayer. 1996. Cannabinoid receptor agonists inhibit glutamatergic synaptic transmission in rat hippocampal cultures. J. Neurosci. 16: 4322-4334.

Shen, M. and S.A. Thayer. 1998. The cannabinoid agonist Win55,212-2 inhibits calcium channels by receptor-mediated and direct pathways in cultured rat hippocampal neurons. Brain Res. 783: 77-84.

Stella, N., P. Schweitzer, and D. Piomelli. 1997. A second endogenous cannabinoid that modulates long-term potentiation. Nature 388: $773-778$.

Stevens, C.F. 1998. A million dollar question: Does LTP $=$ memory? Neuron 20: 1-2.

Sullivan, J.M. 1999. Mechanisms of cannabinoid-receptor-mediated inhibition of synaptic transmission in cultured hippocampal pyramidal neurons. J. Neurophysiol. 82: 1286-1294.

Takahashi, T. and A. Momiyama. 1993. Different types of calcium channels mediate central synaptic transmission. Nature 366: 156-158.

Terranova, J.P., J.C. Michaud, G. Le Fur, and P. Soubrie. 1995. Inhibition of long-term potentiation in rat hippocampal slices by anandamide and WIN55212-2: Reversal by SR141716 A, a selective antagonist of CB1 cannabinoid receptors. Naunyn-Schmiedebergs Arch. Pharmakol. 352: 576-579.

Terranova, J.P., J.J. Storme, N. Lafon, A. Perio, M. Rinaldi-Carmona, G. Le Fur, and P. Soubrie. 1996. Improvement of memory in rodents by the selective CB1 cannabinoid receptor antagonist, SR 141716. Psychopharmacology Ser. (Berl) 126: 165-172.

Tsou, K., S. Brown, M.C. Sanudo-Pena, K. Mackie, and J.M. Walker. 1998. Immunohistochemical distribution of cannabinoid CB1 receptors in the rat central nervous system. Neuroscience 83: 393-411.

Tsou, K., K. Mackie, M.C. Sanudo-Pena, and J.M. Walker. 1999. Cannabinoid CB1 receptors are localized primarily on cholecystokinin-containing GABAergic interneurons in the rat hippocampal formation. Neuroscience 93: 969-975.

Twitchell, W., S. Brown, and K. Mackie. 1997. Cannabinoids inhibit N- and $\mathrm{P} / \mathrm{Q}$-type calcium channels in cultured rat hippocampal neurons. $J$. Neurophysiol. 78: 43-50.

Vardaris, R.M. and D.J. Weisz. 1977. Delta9-tetrahydrocannabinol and the hippocampus: Effects on CA1 field potentials in rats. Brain Res. Bull. 2: $181-187$.

Weisz, D.J., D.L. Gunnell, T.J. Teyler, and R.M. Vardaris. 1982. Changes in hippocampal CA1 population spikes following administration of delta-9-THC. Brain Res. Bull. 8: 155-162.

Wheeler, D.B., A. Randall, and R.W. Tsien. 1994. Roles of N-type and Q-type $\mathrm{Ca}^{2+}$ channels in supporting hippocampal synaptic transmission. Science 264: 107-111. 


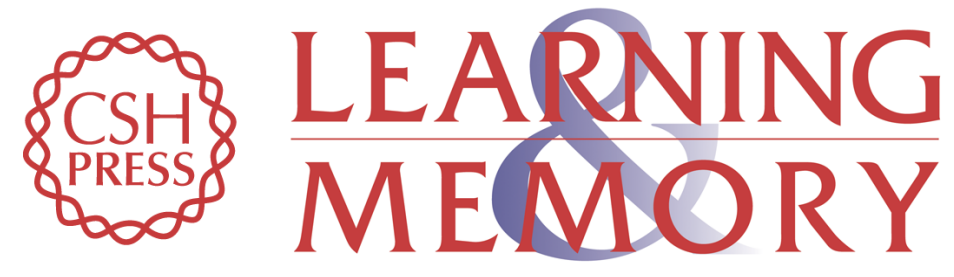

\section{Cellular and Molecular Mechanisms Underlying Learning and Memory Impairments Produced by Cannabinoids}

Jane M. Sullivan

Learn. Mem. 2000, 7:

Access the most recent version at doi:10.1101//m.7.3.132

References This article cites 57 articles, 18 of which can be accessed free at:

http://learnmem.cshlp.org/content/7/3/132.full.htmI\#ref-list-1

License

Email Alerting Receive free email alerts when new articles cite this article - sign up in the box at the Service top right corner of the article or click here. 